\title{
Using Estimated Models to Assess Nominal and Real Rigidities in the United Kingdom*
}

\author{
Güneş Kamber ${ }^{a}$ and Stephen Millard ${ }^{b}$

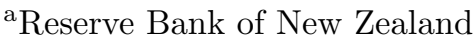 \\ ${ }^{\mathrm{b}}$ Bank of England and Durham Business School
}

This paper aims to contribute to our understanding of inflation dynamics in the United Kingdom by estimating two dynamic stochastic general equilibrium models and assessing the role of nominal and real rigidities within them. We first obtain an empirical representation of the monetary transmission mechanism in the United Kingdom and then estimate the models by minimizing the difference between this representation and its model equivalents. We find that both models can explain the data reasonably well without relying on undue amounts of price and wage stickiness.

JEL Codes: E31, E52.

\section{Introduction}

Most monetary policymakers focus on achieving price stability: typically defined as low and stable inflation. In order to achieve price stability, however, it is important to understand what the dynamics of prices (and inflation) are, what drives them, and-perhaps most importantly - how monetary policy fits into this, i.e., how the

${ }^{*}$ Copyright (C) 2012 Bank of England. The views expressed in this paper are those of the authors, and not necessarily those of the Bank of England or the Reserve Bank of New Zealand. The authors would like to thank Emilio Fernandez-Corugedo, Nicolas Groshenny, Ozer Karagedikli, Philip Liu, Simon Price, Konstantinos Theodoridis, Antonella Trigari and seminar participants at the Bank of England, Université Paris 1 Panthéon Sorbonne, TCMB, CEPII, RBNZ, University of Otago, University of Durham, T2M, the 2009 RES Annual Meeting, PET 2009, and the 2009 Money, Macro and Finance Conference for useful comments. The usual disclaimer applies. Part of this research was conducted while the first author was visiting the Bank of England, for whose hospitality he is thankful. Author e-mails: Gunes.Kamber@rbnz.govt.nz and Stephen.Millard@bankofengland.co.uk. 
monetary transmission mechanism works. In this paper, we aim to contribute to our understanding of the monetary transmission mechanism in the United Kingdom. We do this in the context of two macroeconomic models: those of Smets and Wouters (2003) and Gertler, Sala, and Trigari (2008). We use the minimum distance approach to estimate these models using UK data, where we estimate the parameters of our models so as to match as closely as possible the responses of variables to a movement in interest rates, i.e., the monetary transmission mechanism. The Smets and Wouters (2003) model has become a "workhorse" dynamic stochastic general equilibrium (DSGE) model and has been estimated using Bayesian methods on both U.S. and euro-area data. But in the Smets and Wouters (2003) model, as is the case for most models based on the New Keynesian Phillips curve framework, the labor market is modeled as a spot market with no realistic distinction between heads and hours. ${ }^{1}$ A long tradition in monetary economics, starting with Phillips (1958), has assigned labor market frictions and, in particular, wage-setting frictions, a central role in inflation dynamics. This motivates consideration of the Gertler, Sala, and Trigari (2008) model in which the labor market is modeled more explicitly within the New Keynesian framework. Specifically, the model appends a variant of the Mortensen and Pissarides (1994) model of search and matching frictions to the New Keynesian framework.

Our paper makes three contributions to the literature. First, estimating the Gertler, Sala, and Trigari (2008) model on UK data and comparing our estimates with those obtained in the original paper using U.S. data enables us to assess how similar the United Kingdom is to the United States and where differences may lie, e.g., in the degree of nominal price and wage rigidity or in the bargaining power of workers. Second, by comparing our results across the two models, we can assess the importance of explicitly modeling unemployment for understanding inflation dynamics; in particular, once one has controlled for total hours worked/employment, does unemployment/labor market tightness gives any additional information about the effects of movements in interest rates on

\footnotetext{
${ }^{1}$ In Smets and Wouters (2003), workers are assumed to have market power with the result that there is a difference between the amount of labor supplied in equilibrium and the amount that would be supplied if this distortion were not there.
} 
inflation? The results of Gertler, Sala, and Trigari (2008) suggest that in the United States, the Smets and Wouters (2003) model explains inflation and output well enough and that the gain to introducing unemployment explicitly is solely that one can tell coherent stories about unemployment itself; a key point of our paper is to see whether or not this result holds for the United Kingdom. Third, we are able to assess the importance of nominal and real rigidities within the United Kingdom by comparing the fit of the two models with and without such rigidities.

We find that both models are able to explain reasonably well the dynamic responses of the macroeconomic variables we considered in the United Kingdom to a shock to interest rates. In order to achieve this, our estimates imply that wages are reset about once every three quarters, and prices every year and a half. The estimated price rigidity is higher than the recent survey evidence on price durations reported in Greenslade and Parker (2012) but is in line with DiCecio and Nelson (2007), which estimates price rigidities to be higher than wage rigidities in the United Kingdom. But, in order to match the impulse responses, we also need a large degree of indexation in price and wage setting. This finding contrasts with the estimates of Groth, Jaaskela, and Surico (2006), who find much less evidence of wage and price indexation in their estimated UK Phillips curves.

The paper is structured as follows. We first use a structural vector autoregression (SVAR) approach to obtain an empirical representation of the monetary transmission mechanism, i.e., how a movement in interest rates affects some important macroeconomic variables in the United Kingdom. We then discuss the two models we are going to estimate before moving on to discuss the estimation strategy. Our aim is to obtain values for the parameters of the two models that enable them to replicate the empirical representation of the monetary transmission mechanism we found in our initial SVAR analysis. After discussing our estimation strategy, we present our results before concluding.

\section{Monetary Transmission in the United Kingdom}

We estimate a nine-variable SVAR in order to identify the effects of a monetary policy shock on macroeconomic variables in the United 
Kingdom. Our sample runs from 1979:Q2 to 2007:Q4. We chose to start our sample in 1979:Q2 on account of the argument in DiCecio and Nelson (2007) that this date constitutes an important monetary and government policy regime change. There have of course been subsequent changes in the UK monetary policy regime, but given the problems with estimating a VAR on a short sample, we chose to follow DiCecio and Nelson (2007) and assume that these different monetary policy regimes were all compatible with the same implied policy reaction function.

We estimate a VAR with the following nine variables:

$$
\mathbf{Y}_{t}=\left(\begin{array}{c}
\ln \text { (output) } \\
\Delta \ln \text { (output deflator) } \\
\ln \text { (consumption) } \\
\ln \text { (investment) } \\
\ln \text { (real wage) } \\
\ln \text { (productivity) } \\
\text { capacity utilization } \\
\ln (\text { relative investment price) } \\
\text { nominal interest rate }
\end{array}\right)
$$

These variables are the same as used by Altig et al. (2011), although they also included the money supply. We made sure that the variables we used in the VAR were consistent with their model counterparts by using consumption spending on non-durables per head of population for consumption, $C$; business investment plus consumption spending on durables per head of population for investment, $I$; and the sum of these two series for output $(Y=C+I)$. Our series for inflation used the implied output deflator, given our definition of output. We calculated our real wage series by dividing the nominal private sector wage per worker by this deflator. We calculated the relative price of investment goods implied by our investment and output series. For productivity, we divided our output measure by private sector employment per head of population. Capacity utilization was constructed as described on page 205 of Harrison et al. (2005). Finally, for the interest rate we used the Bank of England's policy rate.

In order to obtain sensible results from the VAR - and to make the variables used comparable to the model - it was necessary to 


\section{Figure 1. Impulse Responses to Monetary Policy Shock}
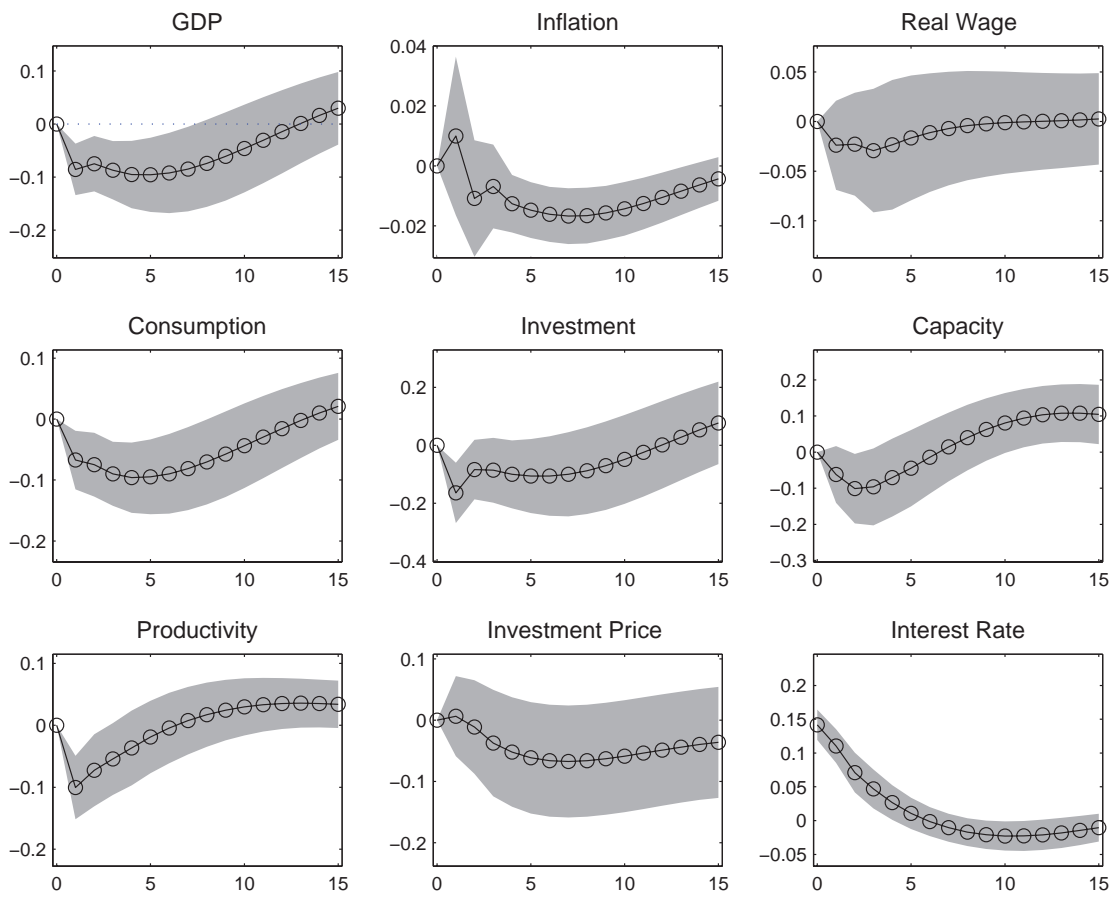

detrend the variables in the VAR. We chose to assume a log-linear trend when detrending each of our variables, as this seemed to fit the data reasonably well and ensured that the resulting data were stationary. We examined the robustness of our results to alternative assumptions about the trends and we found the results to be robust to using a quadratic trend, a cubic trend, or an HP filter to detrend the data.

We identify the monetary policy shocks using a conventional Choleski decomposition by ordering the nominal interest rate last.

Figure 1 displays the impulse response functions (IRFs) to a onestandard-deviation increase in the interest rate. $^{2}$ The solid line is the estimated response and the shaded areas correspond to 90 percent

\footnotetext{
${ }^{2}$ Responses are measured as the percentage deviations from trend except for inflation and interest rates, which are measured as the percentage-point deviation from base.
} 
confidence intervals. We summarize our results by comparing them with the effect of monetary policy shocks in the United States. ${ }^{3}$ The following results are similar:

- The responses of output, consumption, investment, and capacity utilization are hump shaped. The peak response of output occurs five quarters after the shock.

- The inflation response is hump shaped with a peak after two years, and the effect on inflation of a monetary policy shock dies out after three years. There is also a price puzzle lasting one period, but this is not statistically significant.

- The responses of the relative price of investment and real wages are effectively zero. ${ }^{4}$ For the relative price of investment goods we might expect this; for real wages, the result suggests that there are significant real wage rigidities in the United Kingdom.

- The peak response of productivity is one period after the shock. Given the response of GDP, this path suggests that the adjustment in labor input occurs with a lag relative to the response of output.

- Following a monetary policy shock, the investment response is only slightly higher than the response of output. Cyclical investment is, however, 2.2 times more volatile than cyclical output. ${ }^{5}$

\section{Theoretical Models}

In this section, we discuss the two small-scale DSGE models that we will be estimating with UK data. The models are almost identical except for the functioning of the labor market. The first model, developed in Smets and Wouters (2003) and Christiano,

\footnotetext{
${ }^{3}$ Our comparison takes the results in Altig et al. (2011) as the "benchmark" response to a monetary policy shock in the United States.

${ }^{4}$ We do not use the response of relative price of investment in the estimation, as the theoretical models assume that this variable is not affected by monetary policy shocks.

${ }^{5}$ We define cyclical investment and output as the logarithm of the quarterly investment and output series that are HP filtered with a smoothing parameter of 1,600 .
} 
Eichenbaum, and Evans (2005), assumes the household is a monopoly supplier of a differentiated labor service, while the second, Gertler, Sala, and Trigari (2008), represents the labor market with search and matching frictions. This difference is key since it introduces "unemployment" into the model in such a way as to match how unemployment is measured in the data. Shimer (2005) showed that the search model was unable to match the volatility of unemployment in the data, and other papers, largely sparked by this critique, have sought to improve the modeling or calibration of the labor market in order to match better the unemployment data, e.g., Fujita and Ramey (2005), Yashiv (2006), and Gertler and Trigari (2009). We are, however, more interested in whether including unemployment enables us better to match the empirical facts we established in the previous section. The rationale for thinking that it might comes from the belief that sluggish responses in labor market variables to shocks are a natural place to look for the origins of the sluggish response of inflation to shocks. In terms of the New Keynesian framework, which nests both of these models, labor market frictions will alter aggregate marginal cost. ${ }^{6}$

The dynamic equations of the models are summarized in tables 1 and 2. (We refer to Smets and Wouters 2003 and Gertler, Sala, and Trigari 2008 for details on the derivation of reduced-form equations.) Both models have nominal rigidities in the goods and labor markets and real rigidities such as habit formation in consumption, investment adjustment costs, and variable capital utilization. The dynamics of the models relating to consumption, investment, capital accumulation, and capital utilization are identical. Therefore, table 2 only shows the reduced-form relationships in the Gertler, Sala, and Trigari (2008) model that are modified with the introduction of unemployment. Tables 1 and 2 also make clear that, as in Rotemberg and Woodford (1997) and Christiano, Eichenbaum, and Evans (2005), we ensure that monetary policy shocks have a zero impact on the other endogenous variables within period, consistent with the restrictions that we have imposed in the VAR. This restriction

\footnotetext{
${ }^{6}$ Thus, the labor market was seen as a source of "real rigidities." For an overview of the extensive literature on real rigidities more generally, see Woodford (2003).
} 


\section{Table 1. Linearized Model Equations: Smets and Wouters (2003)}

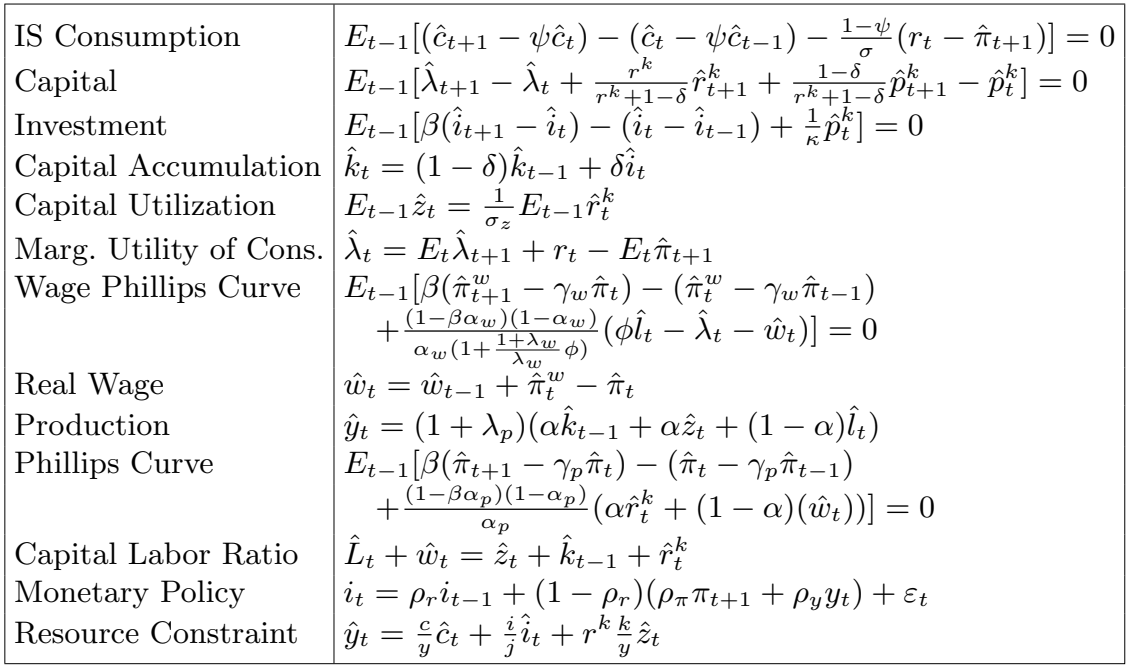

is imposed via the timing of expectations shown in tables 1 and 2 . We describe the parameters of the models in the next section.

\section{Estimation}

We evaluate the models following the minimum distance estimation strategy developed in Rotemberg and Woodford (1997), Altig et al. (2011), Boivin and Giannoni (2006), and Meier and Muller (2006). As Smets and Wouters (2003) stress, this strategy helps to focus on empirical properties that the model has been developed to explain. The objective is to minimize the difference between empirical and model-based impulse responses.

Formally, define $\mathbf{J}$ as the vector containing the empirical impulse responses resulting from our VAR estimation and $\mathbf{J}(\boldsymbol{\theta})$ as the vector of theoretical impulse responses of the DSGE model where the vector $\boldsymbol{\theta}$ contains the parameters we are looking to estimate.

$$
L=\min _{\boldsymbol{\theta}}\left[(\mathbf{J}-\mathbf{J}(\boldsymbol{\theta}))^{\prime} \mathbf{W}^{-1}(\mathbf{J}-\mathbf{J}(\boldsymbol{\theta}))^{\prime}\right],
$$




\section{Table 2. Linearized Model Equations: Gertler, Sala and Trigari (2008)}

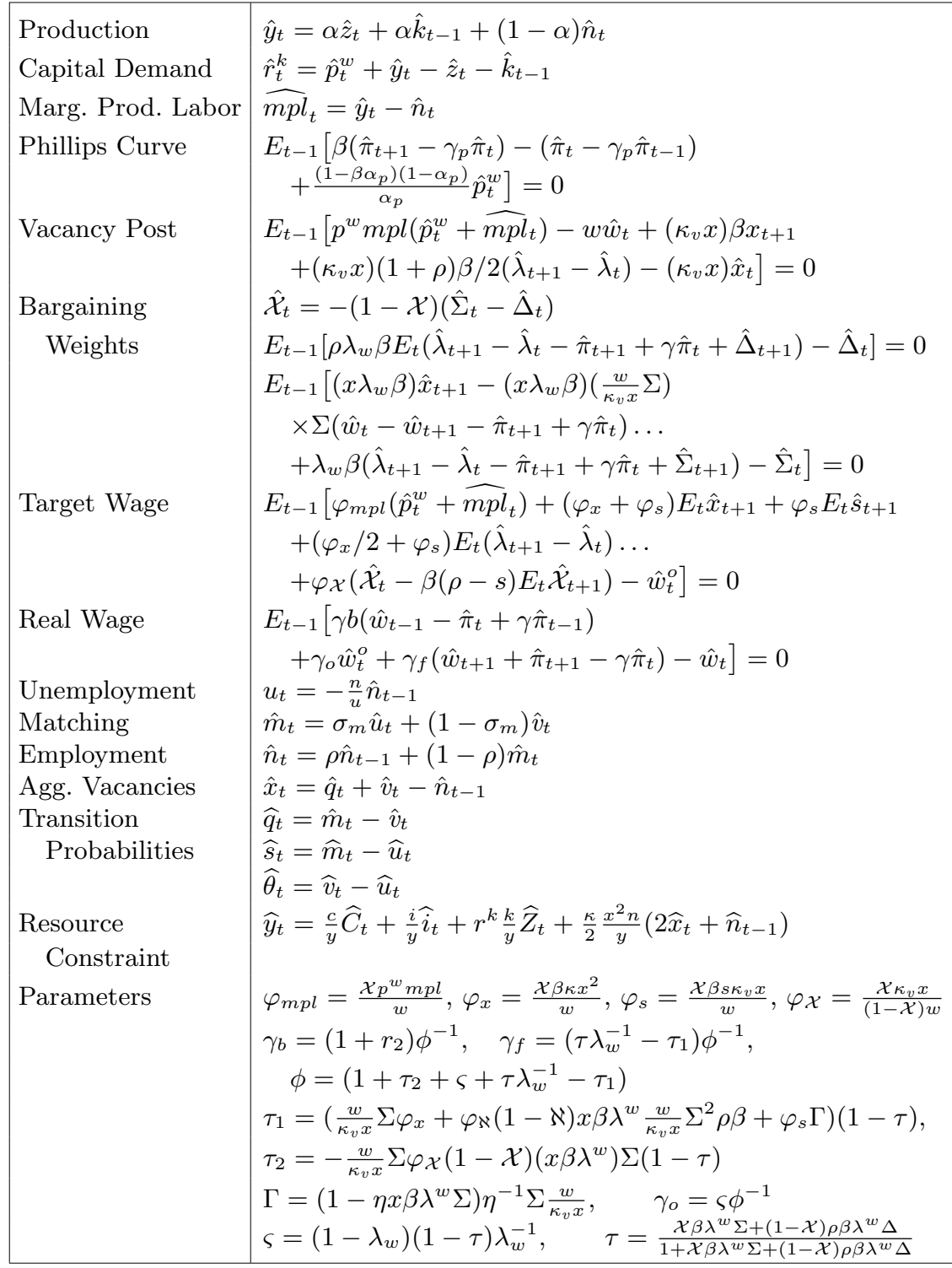


where $\mathbf{W}$ is a diagonal weighting matrix which contains the variance of estimated impulse responses. This weighting matrix gives more weight to more precisely estimated impulse responses and ensures that the resulting model-based impulse responses lie within the estimated confidence intervals.

\subsection{The Smets and Wouters (2003) Model}

Following DiCecio and Nelson (2007), we use the minimum distance approach to estimate the following vector of parameters:

$$
\theta=\left\{\psi, \phi, \gamma_{p}, \gamma_{w}, \alpha_{p}, \alpha_{w}, \kappa, \sigma_{z}, \rho_{R}, \rho_{\pi}, \rho_{y}, \sigma_{m}\right\} .
$$

The remaining parameters are important for determining steadystate relationships rather than the dynamics of the model, so we use values that can be inferred either from the steady-state relationships or from microeconomic studies. In particular, we fix the discount rate, $\beta$, to 0.99 , implying a steady-state annual nominal interest rate of about 4 percent. We fix $\alpha=0.36$ and $\delta=0.025$, values commonly used in the literature, including by DiCecio and Nelson (2007). We adopt a log-utility function $(\sigma=1)$. Finally, the wage markup, $\lambda_{w}$, is set to 0.5 following Smets and Wouters (2003) and the price markup, $\lambda_{p}$, is set to 0.2 following the results reported in Macallan, Millard, and Parker (2008). In the estimation, for all parameters that were restricted by theory to lie between 0 and 1 , we allowed our estimates to take values between 0.01 and 0.99 . For the other parameters, we considered values within large ranges: for the investment adjustment cost parameter, $\kappa$, we considered values between 1 and 40; for the response of interest rates to inflation, $\rho_{\pi}$, we considered values between 1 and 5 ; for the response of interest rates to output, $\rho_{y}$, we considered values between 0 and 0.5 ; for the inverse of the Frisch elasticity of labor supply, $\phi$, we considered values between 0.01 and 5 ; for the capacity utilization parameter, $\sigma_{z}$, we considered values between 0.001 and 10 ; and for the standard deviation of the monetary policy shock, we considered values between $10^{-6}$ and 0.1 .

Table 3 presents the estimated values for the parameters in our benchmark model using information contained in all empirical IRFs. Our estimate for the habit formation parameter is somewhat higher than others (e.g., Fuhrer 2000, DiCecio and Nelson 2007, Harrison 
Table 3. Estimated Parameter Values for the Smets and Wouters (2003) Model

\begin{tabular}{|c|c|c|}
\hline Parameter & & Value \\
\hline$\psi$ & Habit Formation in Consumption & $\begin{array}{c}0.87 \\
(0.04)\end{array}$ \\
\hline$\gamma_{p}$ & Degree of Price Indexation & $\begin{array}{l}1.00 \\
(-)\end{array}$ \\
\hline$\gamma_{w}$ & Degree of Wage Indexation & $\begin{array}{l}1.00 \\
(-)\end{array}$ \\
\hline$\alpha_{p}$ & Probability of Not Being Able to Reset Prices & $\begin{array}{c}0.81 \\
(0.17)\end{array}$ \\
\hline$\alpha_{w}$ & Probability of Not Being Able to Reset Wages & $\begin{array}{c}0.74 \\
(0.12)\end{array}$ \\
\hline$\varnothing$ & Inverse of Labor Supply Elasticity & $\begin{array}{c}1.34 \\
(4.05)\end{array}$ \\
\hline$\kappa$ & Elasticity of Investment Adjustment Costs & $\begin{array}{c}6.17 \\
(4.11)\end{array}$ \\
\hline$\sigma_{z}$ & Elasticity of Capacity Utilization Costs & $\begin{array}{c}0.001 \\
(-)\end{array}$ \\
\hline$\rho_{R}$ & Persistence Parameter in Taylor Rule & $\begin{array}{c}0.77 \\
(0.09)\end{array}$ \\
\hline$\rho_{\pi}$ & Coefficient on Inflation in Taylor Rule & $\begin{array}{l}1.39 \\
(0.98)\end{array}$ \\
\hline$\rho_{y}$ & Coefficient on Output in Taylor Rule & $\begin{array}{c}0.14 \\
(0.22)\end{array}$ \\
\hline$\sigma_{m}$ & Standard Deviation of Monetary Policy Shock & $\begin{array}{c}0.0014 \\
(0.0002) \\
\end{array}$ \\
\hline
\end{tabular}

and Oomen 2010, and Altig et al. 2011) and it implies a substantial role for backward-looking behavior in consumption. The lower bound fixed for the parameter $\sigma_{z}$ is binding, which means that the elasticity of capital utilization with respect to the rental rate of capital tends toward infinity. This finding is in line with the previous estimation results for the United States, though completely out of line with that of DiCecio and Nelson (2007). The reason for this difference is that, in addition to the empirical IRFs used by DiCecio and Nelson (2007) in their estimation, we have also sought to match the empirical IRF of capacity utilization. Our estimates indicate that we 
match this response quite well. But to do this we need the parameter $\sigma_{z}$ to be small compared with DiCecio and Nelson's (2007)'s estimate of infinity. As Altig et al. (2011) point out, variable capital utilization helps the model to match observed inflation persistence by lowering the elasticity of rental rate to monetary policy shocks. Our estimate for the investment adjustment cost is higher than in the United States and the euro area but lower than the previous UK estimate. The reason for this result is that, although investment is more volatile than output at business-cycle frequencies, we find, in line with DiCecio and Nelson (2007), that the investment response after a monetary policy shock is not large. Our estimate for the parameter $\phi$ is 1.34 . It implies that the Frisch elasticity of labor supply is slightly less than one. This value is close to the values generally used in the DSGE literature and it is well known that it is not in accordance with the micro estimates that suggest very low labor supply elasticities. However, we find that this parameter is not estimated very precisely, as it has a large standard deviation.

Our results for the parameters governing the nominal side of the economy suggest that the average duration of wages is slightly less than a year whereas the average duration of prices is almost five quarters. The estimated price rigidity is higher than the recent survey evidence on price durations reported in Greenslade and Parker (2012) but in line with Smets and Wouters (2003) and DiCecio and Nelson (2007), who estimate the price rigidities to be higher than wage rigidities for the euro area and the United Kingdom, respectively. However, DiCecio and Nelson (2007) find that, for the 1979:Q2-2005:Q4 period, there is no nominal wage rigidity while they estimate nominal rigidities in the goods market to be very high, with an average price duration of three and a half years. Again, we are trying to match the IRF for the real wage, in addition to those IRFs matched by DiCecio and Nelson (2007); it is likely that this explains the different result we obtain for the extent of nominal wage rigidity.

Finally, $\gamma_{p}$ and $\gamma_{w}$ are estimated to be equal to the upper bound of one, implying full indexation in both the goods and labor markets. This finding contrasts with the estimates of Smets and Wouters (2003, 2007), and Groth, Jaaskela, and Surico (2006), who find much lower values for the euro area, United States, and United Kingdom, respectively. 


\section{Figure 2. Impulse Response Functions for the Smets and Wouters (2003) Model}
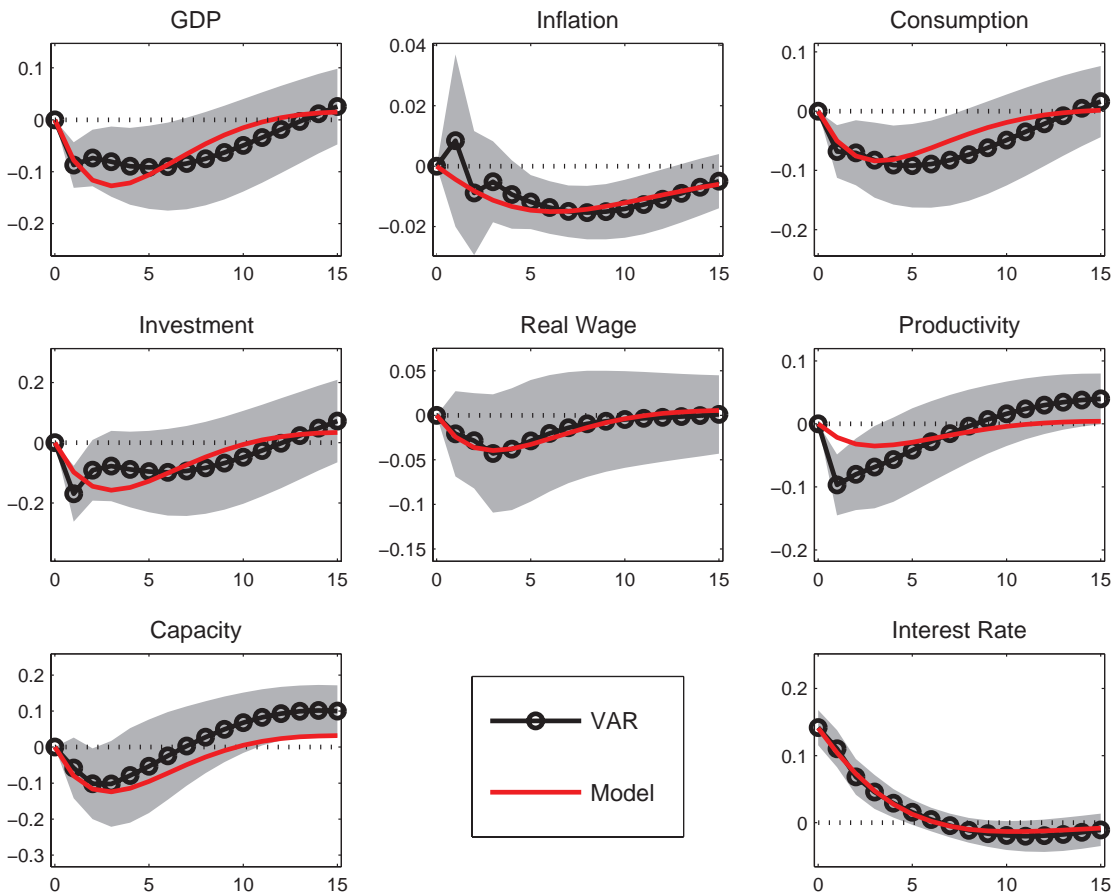

Our results confirm earlier findings in the United States, the euro area, and the United Kingdom that monetary policy exhibits high interest rate smoothing. ${ }^{7}$ The parameters governing the response of the central bank to inflation and output are not very precisely estimated. This is likely to be a result of changes in the monetary policy regime over our sample period which we discussed earlier.

Figure 2 displays the empirical IRFs and the IRFs from the model obtained using the estimated parameter values. Our model does well in explaining the dynamic responses of macroeconomic variables in the United Kingdom to a monetary policy shock. The model predicts negative hump-shaped responses for output, inflation, consumption, investment, productivity, and capacity

\footnotetext{
${ }^{7}$ See, e.g., Clarida, Galí, and Gertler (1998) and Nelson (2003).
} 
utilization. It also predicts a near-zero response of the real wage. All the model IRFs lie within the 90 percent confidence intervals apart from the response of productivity, which is too persistent. This result suggests the need for a better specification of the labor market in the model and helps motivate our estimation of the Gertler, Sala, and Trigari (2008) model in section 4.2.

\subsection{The Gertler, Sala, and Trigari (2008) Model}

The Gertler, Sala, and Trigari (2008) model differs from the Smets and Wouters (2003) model only in its specification of the labor market. In this case, the vector of parameters we wish to estimate is given by

$$
\theta=\left\{\psi, \gamma_{p}, \gamma_{w}, \alpha_{p}, \alpha_{w}, \kappa, \sigma_{z}, \rho_{R}, \rho_{\pi}, \rho_{y}, \bar{b}, \eta, \sigma_{m}\right\} .
$$

Within this model, we estimate two additional parameters relative to the Smets and Wouters (2003) model: the bargaining power of workers, $\eta$, and the flow value of being unemployed, $\bar{b}$. In our estimation we allowed those parameters to lie between zero and one as predicted by theory and used the same ranges discussed previously for the remaining parameters. Again, we were not able to estimate all the parameters of the model, so - following Gertler, Sala, and Trigari (2008) - we used other evidence to set these parameters. Given the lack of direct evidence on the parameters governing labor market flows, we had to calculate these parameters using UK labor market data.

Specifically, we estimated a matching function for the 2001-08 period in order to infer about the elasticities of the matching function with respect to unemployment and vacancies. Our estimation takes a standard approach, as described in Petrongolo and Pissarides (2001). We estimate a log-linear matching function where the dependant variable is outflows from unemployment. In theory, the matching function gives the number of new hires in terms of workers looking for jobs and vacancies. However, the data on unemployment may not reflect the real number of job searchers, as some workers may go from inactivity to activity without declaring themselves as unemployed. But as in Blanchard and Diamond (1989), we assume that, for the United Kingdom, the unemployment rate measured by those claiming unemployment benefit may be a good proxy for all job seekers. 
Table 4. Estimated Parameter Values: Matching Function

\begin{tabular}{|l|c|c|c|c|}
\hline \multirow{2}{*}{ Parameter } & $\begin{array}{c}\text { Claimant } \\
\text { Count }\end{array}$ & \multicolumn{3}{|c|}{ LFS } \\
\cline { 2 - 5 } & Unrestricted & Restricted & Unrestricted & Restricted \\
\hline$\alpha_{1}$ & -0.46 & -0.47 & -0.31 & -0.52 \\
& $(0.74)$ & $(0.02)$ & $(0.38)$ & $(0.02)$ \\
$\alpha_{2}$ & 0.55 & 0.55 & 0.68 & 0.72 \\
& $(0.13)$ & $(0.05)$ & $(0.07)$ & $(0.05)$ \\
$\alpha_{3}$ & 0.44 & & 0.23 & \\
& $(0.15)$ & & $(0.09)$ & \\
$\alpha_{4}$ & -0.0004 & -0.0004 & -0.00011 & -0.00011 \\
CRS Test's & $(0.0001)$ & $(0.0001)$ & $(0.0001)$ & $(0.0001)$ \\
P-value & 0.99 & & 0.57 & \\
$R^{2}$ & 0.41 & 0.42 & 0.63 & 0.64 \\
\hline
\end{tabular}

We also report our estimates using unemployment measured by the Labour Force Survey (LFS).

As in Blanchard and Diamond (1989), we estimate the following equation using OLS:

$$
\ln \left(M_{t}\right)=\alpha_{1}+\alpha_{2} \ln \left(U_{t}\right)+\alpha_{3} \ln \left(V_{t}\right)+\alpha_{4} \text { Trend }+\varepsilon_{t} .
$$

We use monthly data and our estimation period covers 2001:M62008:M6.

Table 4 presents our estimation results. The estimated elasticities of matches with respect to unemployment and vacancies are significant and positive. We also find a small but negative coefficient for the time trend, which implies a decrease over time in the efficiency of the matching technology. As Petrongolo and Pissarides (2001) point out, the estimated weight on unemployment is higher in the United Kingdom than in the United States. This finding is in line with previous matching function estimates of Hellwig, Layard, and Pissarides (1986) and Burda and Wyplosz (1994) for the United Kingdom. One noticeable point is that the estimated values are sensitive to the measure of unemployment we use in the estimation. The LFS unemployment measure is always higher than claimant count 
unemployment and it also yields higher estimates for the elasticity of matches to unemployment. The estimates remain, however, close to the $0.5-0.7$ range considered in the literature.

Most of the empirical studies conclude that a constant return to scale matching function describes the data well. We also tested this assumption. The restriction that the elasticities sum up to 1 is not rejected only when we use claimant count unemployment. When we reestimate the model imposing constant return to scale, the estimated values remain the same. We can therefore confidently set the parameter $\sigma_{u}$ in our estimation to some value between 0.5 and 0.7 .

The other two parameters that we can get from data are $s$, the probability of finding a job for an unemployed worker, and $\rho$, the ratio of surviving jobs at each period (or one minus the separation rate).

We calculate the probability of an unemployed worker finding a job by dividing unemployment outflows by unemployment. This calculation yields a value of 0.55 for $s$, implying an average duration of unemployment of approximately five months. The unemployment series is not, however, consistent with our model, as we are not explicitly modeling the labor market participation decision. In reality, some of the unemployment outflows will be into non-participation, and therefore the implied time taken by unemployed workers to find a job may be a bit higher. As a result, we adopt the slightly lower value of 0.5 for $s$.

To calibrate the job-separation rate, we use data on unemployment inflows. This calculation indicates that the quarterly inflow to unemployment is just 1 percent of total employment. This would imply a value of 99 percent for $\rho=0.99$. Since we do not have data on workers leaving a job and going to inactivity, we revise our calculation upward. In our simulation, we set $\rho$ to 0.95 . Finally, our steady state, when $s=0.5$ and $\rho=0.95$, implies that the steady-state unemployment rate is 9.1 percent. This value is higher than what we observe in the data. Our model does not, however, explicitly model the participation decision, i.e., the possible transitions from inactivity to employment or unemployment. Our higher unemployment rate can be seen as a result of this difference between the model and the data.

Figure 3 displays the empirical IRFs and the IRFs from the model obtained using the estimated parameter values. The model 
Figure 3. Impulse Response Functions for the Gertler, Sala, and Trigari (2008) Model
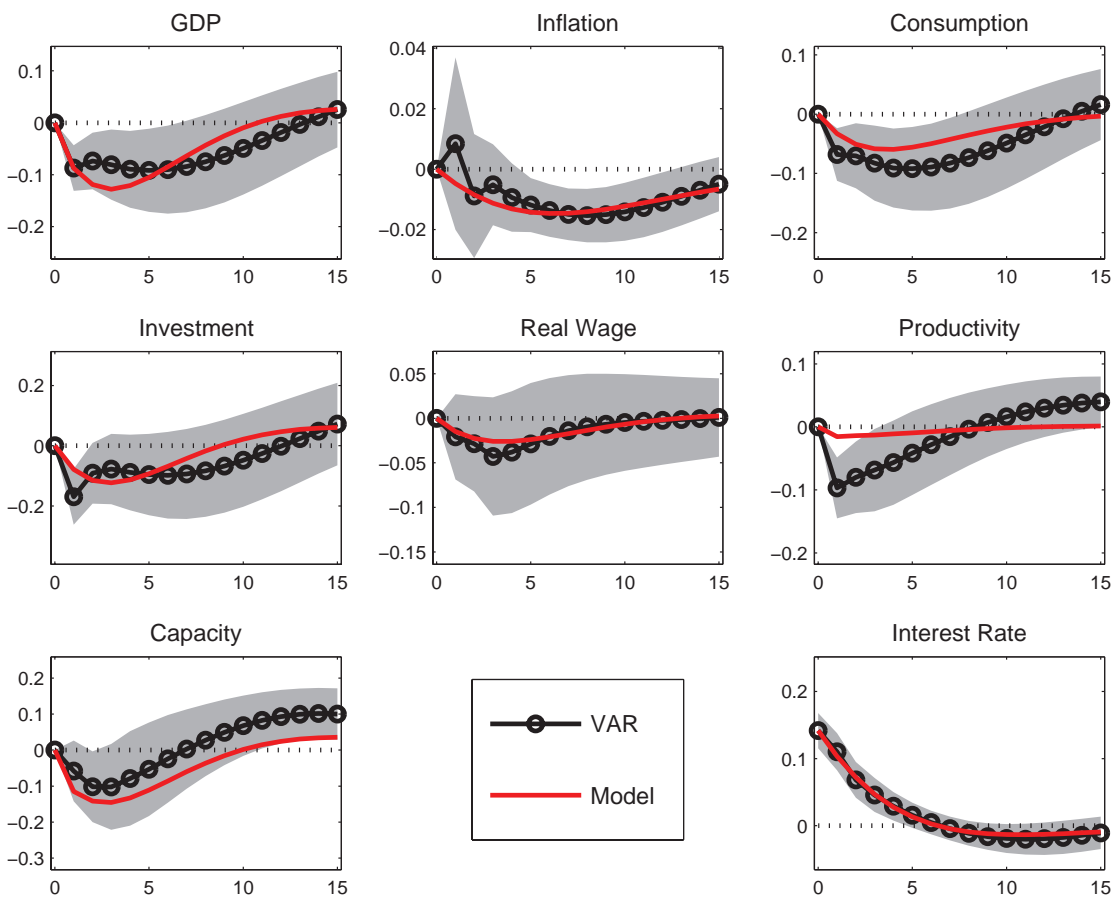

again does well in explaining the dynamic responses of macroeconomic variables in the United Kingdom to a monetary policy shock with negative hump-shaped responses for output, inflation, consumption, investment, and capacity utilization and a near-zero response in real wages. But it seems to do less well at explaining the response of productivity to the shock than the Smets and Wouters (2003) model: essentially, the search frictions result in the productivity response to the shock being dampened, though it is more persistent. Given that the difference between the two models relates to how the labor market is modeled, this result is a little disappointing.

Table 5 presents the estimated values for the parameters in our model. In terms of the parameter estimates for the Gertler, Sala, and Trigari (2008) model, the key difference to those for the Smets and Wouters (2003) model is the degree of wage stickiness we estimate. 
Table 5. Estimated Parameter Values (Gertler, Sala, and Trigari 2008)

\begin{tabular}{|c|c|c|}
\hline Parameter & & Value \\
\hline$\psi$ & Habit Formation in Consumption & $\begin{array}{c}0.90 \\
(0.04)\end{array}$ \\
\hline$\gamma_{p}$ & Degree of Price Indexation & $\begin{array}{l}1.00 \\
(-)\end{array}$ \\
\hline$\gamma_{w}$ & Degree of Wage Indexation & $\begin{array}{l}1.00 \\
(-)\end{array}$ \\
\hline$\alpha_{p}$ & Probability of Not Being Able to Reset Prices & $\begin{array}{c}0.82 \\
(0.16)\end{array}$ \\
\hline$\alpha_{w}$ & Probability of Not Being Able to Reset Wages & $\begin{array}{c}0.60 \\
(0.19)\end{array}$ \\
\hline$\kappa$ & Elasticity of Investment Adjustment Costs & $\begin{array}{c}7.33 \\
(4.77)\end{array}$ \\
\hline$\sigma_{z}$ & Elasticity of Capacity Utilization Costs & $\begin{array}{c}0.00 \\
(-)\end{array}$ \\
\hline$\rho_{R}$ & Persistence Parameter in Taylor Rule & $\begin{array}{c}0.77 \\
(0.09)\end{array}$ \\
\hline$\rho_{\pi}$ & Coefficient on Inflation in Taylor Rule & $\begin{array}{l}1.45 \\
(0.93)\end{array}$ \\
\hline$\rho_{y}$ & Coefficient on Output in Taylor Rule & $\begin{array}{c}0.13 \\
(0.22)\end{array}$ \\
\hline$\eta$ & Workers' Bargaining Power & $\begin{array}{c}0.75 \\
(0.48)\end{array}$ \\
\hline$b$ & Flow Value of Being Unemployed & $\begin{array}{c}0.93 \\
(0.12)\end{array}$ \\
\hline$\sigma_{m}$ & Standard Deviation of Monetary Policy Shock & $\begin{array}{c}0.0014 \\
(0.0002)\end{array}$ \\
\hline
\end{tabular}

In this case, the average duration of wages is estimated to be approximately seven and a half months. In order to match the empirical IRFs, the Gertler, Sala, and Trigari (2008) model needs less nominal wage rigidity due to the presence of search and matching frictions in the labor market. We again estimate wages and prices to be fully indexed and the lower bound for the elasticity of capital utilization costs parameter is binding. We estimate the workers' bargaining power to be equal to 0.75 and the flow value of unemployment relative to the flow value of a worker to the firm at the steady state 
Table 6. Loss Values

\begin{tabular}{|l|r|r|}
\hline & SW & GST \\
\hline Benchmark & 56.14 & 68.02 \\
No Price Rigidities & 62.21 & 74.13 \\
No Wage Rigidities & 135.28 & 79.49 \\
\hline
\end{tabular}

to be 0.93 . The latter is a high value, but — as argued by Hagedorn and Manovskii (2008) - such a high value is necessary for the model to match the relative responses of employment and real wages to shocks.

\subsection{Assessing the Role of Frictions}

We can use the values of our estimated loss function - equation (1) to compare the fit of the two models and assess the role of nominal rigidities. A lower loss value implies that the theoretical monetary transmission mechanism in the estimated variant is closer to the empirical one.

The first line of table 6 shows the loss values for the benchmark models estimation. As we argued earlier, the Gertler, Sala, and Trigari (2008) model does slightly less well than the Smets and Wouters (2003) model in minimizing the distance between the empirical and theoretical IRFs. The inclusion of labor market rigidities via search and matching frictions does not improve the fit of the model. The model has, however, the advantage of allowing us to quantify the effects of shocks on unemployment and job and worker flows.

Next, we turn to the analysis of the role of nominal frictions in the models' ability to match the data. To do so, we reestimate restricted versions of the baseline models without nominal rigidities. The results are presented in table 6 . The second line shows the estimated loss value under the assumption of no price rigidities, i.e., $\gamma_{p}=0$ and $\alpha_{p}=0.01$. The third line is obtained by imposing no nominal wage rigidities in the models, which corresponds to $\gamma_{w}=0$ and $\alpha_{w}=0.01$.

For both models, the loss values are higher in restricted models, suggesting that the absence of nominal rigidities deteriorates the models' fit. This result indicates that nominal rigidities in both the 
goods and labor markets are important in explaining the monetary transmission mechanism in the United Kingdom.

It is worth noting that the ability of the model to match the monetary transmission mechanism is lower when we shut down nominal wage rigidities. The deterioration in model fit is much larger in the Smets and Wouters (2003) model. This is in line with our baseline estimate of lower nominal wage rigidities in the Gertler, Sala, and Trigari (2008) model. This model seems to rely less on nominal wage rigidities thanks to search and matching frictions in the labor market.

\section{Conclusion}

In this paper, we used the minimum distance approach to estimate the DSGE models of Smets and Wouters (2003) and Gertler, Sala, and Trigari (2008) using UK data. This was motivated by our interest in understanding inflation dynamics and the monetary transmission mechanism. In particular, we were motivated by a belief that labor market frictions and, in particular, wage-setting frictions play a central role in the monetary transmission mechanism. We found that both models were able to explain reasonably well the dynamic responses of the macroeconomic variables we considered in the United Kingdom to a shock to interest rates without relying on undue amounts of wage and price stickiness: our estimates implied that wages are reset about once every three quarters, and prices every year and a half. But in order to match the impulse responses, we did need a large degree of indexation in price and wage setting.

Unfortunately, neither model was able to satisfactorily explain the responses of productivity and employment. This suggests that it may be worth thinking more about the costs of adjusting labor input if we are to explain movements in employment as well as we can explain movements in output. We leave this for future research. More generally, our results leave us with a big question: given that the Smets and Wouters (2003) model was able to match the implied impulse response functions fairly well, what is the role, if any, of search and matching frictions and unemployment in the monetary transmission mechanism? We also leave finding an answer to that question to future research. 


\section{References}

Altig, D., L. Christiano, M. Eichenbaum, and J. Linde. 2011. "FirmSpecific Capital, Nominal Rigidities and the Business Cycle." Review of Economic Dynamics 14 (2): 225-47.

Blanchard, O. J., and P. Diamond. 1989. "The Beveridge Curve." Brookings Papers on Economic Activity 20 (1): 1-76.

Boivin, J., and M. P. Giannoni. 2006. "Has Monetary Policy Become More Effective?" Review of Economics and Statistics 88 (3): $445-62$.

Burda, M., and C. Wyplosz. 1994. "Gross Worker and Job Flows in Europe." European Economic Review 38 (6): 1287-1315.

Christiano, L., M. Eichenbaum, and C. Evans. 2005. "Nominal Rigidities and the Dynamic Effects of a Shock to Monetary Policy." Journal of Political Economy 113 (1): 1-45.

Clarida, R., J. Galí, and M. Gertler. 1998. "Monetary Policy Rules in Practice: Some International Evidence." European Economic Review 42 (6): 1033-67.

DiCecio, R., and E. Nelson. 2007. "An Estimated DSGE Model for the United Kingdom." Review (Federal Reserve Bank of St. Louis) 89 (4): 215-32.

Fuhrer, J. 2000. "Habit Formation in Consumption and Its Implications for Monetary-Policy Models." American Economic Review 90 (3): 367-90.

Fujita, S., and G. Ramey. 2005. "The Dynamic Beveridge Curve." Federal Reserve Bank of Philadelphia Working Paper No. 05-22.

Gertler, M., L. Sala, and A. Trigari. 2008. "An Estimated Monetary DSGE Model with Unemployment and Staggered Nominal Wage Bargaining." Journal of Money, Credit and Banking 40 (8): 1713-64.

Gertler, M., and A. Trigari. 2009. "Unemployment Fluctuations with Staggered Nash Wage Bargaining." Journal of Political Economy 117 (1): 38-86.

Greenslade, J. V., and M. Parker. 2012. "New Insights into PriceSetting Behaviour in the UK: Introduction and Survey Results." Economic Journal 122 (558): F1-F15.

Groth, C., J. Jaaskela, and P. Surico. 2006. "Fundamental Inflation Uncertainty." Bank of England Working Paper No. 309. 
Hagedorn, M., and I. Manovskii. 2008. "The Cyclical Behavior of Equilibrium Unemployment and Vacancies Revisited." American Economic Review 98 (4): 1692-1706.

Harrison, R., K. Nikolov, M. Quinn, G. Ramsay, A. Scott, and R. Thomas. 2005. The Bank of England Quarterly Model. London: Bank of England.

Harrison, R., and O. Oomen. 2010. "Evaluating and Estimating a DSGE Model for the United Kingdom." Bank of England Working Paper No. 380.

Hellwig, M., R. Layard, and C. Pissarides. 1986. "Unemployment and Vacancies in Britain." Economic Policy 1 (3): 500-59.

Macallan, C., S. P. Millard, and M. Parker. 2008. "The Cyclicality of Mark-Ups and Profit Margins for the United Kingdom: Some New Evidence." Bank of England Working Paper No. 351.

Meier, A., and G. Muller. 2006. "Fleshing Out the Monetary Transmission Mechanism: Output Composition and the Role of Financial Frictions." Journal of Money, Credit and Banking 38 (8): 2099-2134.

Mortensen, D., and C. Pissarides. 1994. "Job Creation and Job Destruction in the Theory of Unemployment." Review of Economic Studies 61 (3): 397-415.

Nelson, E. 2003. "UK Monetary Policy 1972-1997: A Guide Using Taylor Rules." In Central Banking, Monetary Theory and Practice: Essays in Honour of Charles Goodhart, ed. P. Mizen, 195216. Edward Elgar.

Petrongolo, B., and C. A. Pissarides. 2001. "Looking into the Black Box: A Survey of the Matching Function." Journal of Economic Literature 39 (2): 390-431.

Philips, A. W. 1958. "The Relationship between Unemployment and the Rate of Change of Money Wages in the United Kingdom, 1861-1957." Economica 25 (November): 283-99.

Rotemberg, J., and M. Woodford. 1997. "An Optimization-Based Econometric Framework for the Evaluation of Monetary Policy." NBER Macroeconomics Annual 12: 297-346.

Shimer, R. 2005. "The Cyclical Behavior of Equilibrium Unemployment, Vacancies, and Wages: Evidence and Theory." American Economic Review 95 (1): 25-49. 
Smets, F., and R. Wouters. 2003. "An Estimated Dynamic Stochastic General Equilibrium Model of the Euro Area." Journal of the European Economic Association 1 (5): 1123-75.

. 2007. "Shocks and Frictions in US Business Cycles: A Bayesian DSGE Approach." American Economic Review 97 (3): 586-606.

Woodford, M. 2003. Interest and Prices. Princeton, NJ: Princeton University Press.

Yashiv, E. 2006. "Evaluating the Performance of the Search and Matching Model." European Economic Review 50 (4): 909-36. 